\title{
Late acute thrombosis after paclitaxel eluting stent implantation
}

\author{
F Liistro, A Colombo
}

\begin{abstract}
Late (more than six months) total occlusion after coronary stenting is a progressive phenomenon occurring in approximately $4 \%$ of patients, leading to acute myocardial infarction in less than $0.5 \%$. The process must be related to severe and progressive intimal hyperplasia. In patients receiving coronary stenting with simultaneous brachytherapy, late total occlusion has been reported at a higher rate and to be related to stent thrombosis rather than intimal hyperplasia. Late total occlusion presenting with an acute clinical event seven months after the implantation of a paclitaxel drug eluting stent is reported. The occlusion developed soon after the interruption of ticlopidine treatment, suggesting that the event had a thrombotic genesis and that the risk is not confined to the first six month period.

(Heart 2001;86:262-264)
\end{abstract}

Keywords: paclitaxel eluting stent; late thrombosis

Vessel shrinkage after balloon angioplasty and intimal hyperplasia after coronary stenting have been indicated as predominant factors for restenosis and late total occlusion after percutaneous coronary intervention in nonirradiated coronary segments. In patients undergoing coronary stenting with simultaneous brachytherapy, late total occlusion has been observed at a higher rate and to be related to stent thrombosis rather than occlusive intimal hyperplasia. ${ }^{1}{ }^{2}$

The new concept of local drug delivery by coated stents has greatly increased the interest of interventional cardiologists in the pharmacological approach to restenosis. Drug eluting stents couple the mechanical and scaffolding properties of a stent, necessary to optimise the angiographic result, with the requirement for a pharmacological agent to facilitate recovery of the vessel from the injury caused by the stent implantation itself. In addition it offers the possibility of focal therapeutic drug effect within the target tissue, allowing higher drug concentrations at the site of vascular injury without serious side effects arising from systemic administration.

Paclitaxel interferes with cellular migration and proliferation primarily by stabilising microtubules and it has been shown to reduce intimal hyperplasia in animal models of vascular injury. ${ }^{34}$ In addition, paclitaxel may alter inflammatory cell activity, directly linked to the genesis of stent induced neointima, by enhancing macrophage production of nitric oxide, prostaglandins, and other cytokines. The rapid cellular uptake caused by the highly lipophilic character of paclitaxel in association with the unique mode of action supports a long lasting antiproliferative effect even after a brief, single dose application. A recent clinical registry of 30 patients treated for de novo lesions with paclitaxel eluting stent implants found an extremely low rate of in stent restenosis at the six month angiographic follow up and no target vessel revascularisation at the two year clinical follow up. ${ }^{5}$ We report a case of abrupt late total occlusion that developed seven months after implantation of a Quanam paclitaxel eluting stent. The occlusion occurred while the patient was taking aspirin and soon after the interruption of ticlopidine treatment.

\section{Case description}

Coronary angiography was performed in a 49 year old man for unstable angina following a recent (less than six weeks) anterior myocardial infarction. The risk factors for coronary artery disease were hypertension, family history for coronary artery disease, and hypercholesterolaemia. His medical history was negative for other significant diseases. The baseline angiogram showed a left anterior descending coronary artery occluded in the mid segment (fig 1A) with collateral flow from the right coronary artery filling the distal part of the vessel. Left ventricle angiography showed mild hypokinesia in the anterior wall. The patient was enrolled in a randomised study evaluating a drug coated stent versus a non-coated stent to lower angiographic and clinical restenosis. A paclitaxel eluting stent was assigned by the randomisation code. After predilatation with a $2.5 \times 20 \mathrm{~mm}$ Adante balloon (Boston Scientific, Manhasset, Massachusetts, USA), a Quads-QP2 $3.0 \times 17 \mathrm{~mm}$ stent was implanted (Quanam Medical Corp, Santa Clara, California, USA) inflated at $12 \mathrm{~atm}$, achieving an optimal result with a final minimal diameter of $2.95 \mathrm{~mm}$ and a $-3.4 \%$ diameter stenosis (fig $1 \mathrm{~B}$ ). The patient was discharged on the following day in stable condition and taking aspirin $100 \mathrm{mg}$ daily and ticlopidine $250 \mathrm{mg}$ twice a day, to be continued for six months. Six months later the patient 

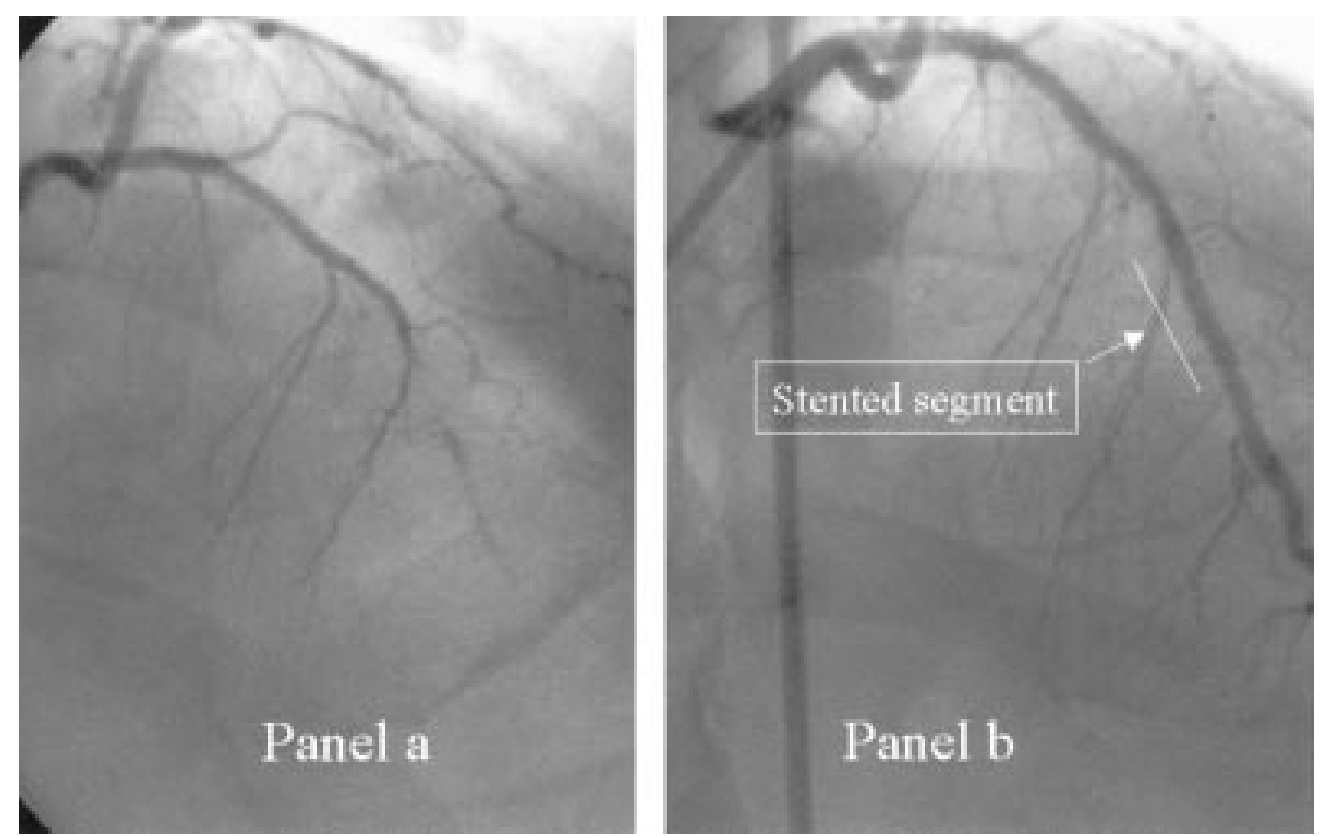

Figure 1 (a) Baseline angiogram of the left coronary artery showing the occlusion of the left anterior descending artery in the mid-segment. (arrows). (b) Optimal immediate angiographic result after implantation of a paclitaxel eluting stent.

underwent control coronary angiography, which showed a persistent optimal result in the treated artery, with no evidence of in stent intimal hyperplasia (fig 2). After control coronary angiography the patient was switched from the combined antiplatelet treatment with aspirin and ticlopidine to aspirin alone. Fifteen days later the patient was admitted to hospital with an acute anterior myocardial infarction (maximal creatine kinase $1160 \mathrm{U} / \mathrm{dl}$ ). The subsequent coronary angiogram showed a total occlusion of the left anterior descending coronary artery in the stented segment with collaterals from the right coronary system filling the distal part of the vessel (fig 3). An attempt to cross the lesion with a wire was unsuccessful and the patient was scheduled for coronary artery bypass grafting.

\section{Discussion}

Late total occlusion after coronary stent implantation is a progressive phenomenon that occurs in approximately $4 \%$ of patients when



Figure 2 Six month angiographic follow up showing persistent optimal result in the stented segment (arrow) with no evidence of intimal hyperplasia. radiation therapy is not used; it leads to acute myocardial infarction in less than $0.5 \%$ of patients. In contrast, several recent reports describe a higher incidence $(6.6 \%)$ of acute thrombotic clinical events $2-15$ months after percutaneous coronary intervention with simultaneous brachytherapy. ${ }^{12}$ In the case presented here, the index procedure ended with an optimal result that was maintained at six months with no evidence of intimal hyperplasia.

Preliminary data from studies in animals and humans show that stent based paclitaxel delivery reduced stent induced intimal thickening. ${ }^{34}$ The time correlation between angiographic follow up and the clinical event excludes intimal hyperplasia as pathogenic phenomenon of the event. Furthermore, the observation that the abrupt vessel occlusion at the stent site occurred soon after the interruption of combined antiplatelet treatment with aspirin and ticlopidine suggests that the late clinical event had a thrombotic genesis. Possible mechanisms responsible for late thrombosis may be the delayed or incomplete reendothelialisation of the stent struts in addition to stent thrombogenicity or neointimal dysfunction determined by paclitaxel. Histological characterisation of tissue responses in the presence of paclitaxel in animals indicates that healing is arrested, with sustained (up to six months) presence in the neointima of inflammatory cells as part of this delayed healing. ${ }^{6}$ Such an incomplete healing process may prolong the period of vessel wall thrombogenicity, as observed after endovascular radiation therapy. ${ }^{7}$ In addition, although animal studies showed that re-endothelialisation of the injured segment was affected only at a high dose of paclitaxel, ${ }^{8}$ these results cannot be directly transferred to the human situation. Until large studies address the timing of complete vessel healing after paclitaxel eluting 



Panel $\mathrm{c}$

Figure 3 (a) Left coronary angiography showing the late total occlusion in the stented segment (magnified in c). (b) Angiography of the right coronary artery with collateral filling of the left anterior descending coronary artery in the segment distal to the occlusion.

stent implantation or the role of endothelial dysfunction is better defined, the clinician should consider the use of combined treatment with two antiplatelet agents indefinitely (aspirin plus ticlopidine or aspirin plus clopidogrel).
CONCLUSION

This single case report highlights the problem that late coronary thrombosis following paclitaxel eluting stent implantation may be an important limitation of restenosis prevention by some drug eluting stents. In the absence of other data, we think that combined antiplatelet treatment should be continued in the long term, unless it is contraindicated.

1 Costa MA, Sabat M, van der Giessen WJ, et al. Late coronary occlusion after intracoronary brachytherapy. Circulation 999;100:789-92.

2 Teirstein PS, Massullo V, Jani S, et al. Three-year clinical and angiographic follow-up after intracoronary radiation: results of a randomized clinical trial. Circulation 2000;101: $360-5$.

3 Herdeg C, Oberhoff M, Baumbach A, et al. Local paclitaxel delivery for the prevention of restenosis: biological effects and efficacy in vivo. 7 Am Coll Cardiol 2000;35:1969-76.

4 Heldman AW, Cheng L, Jenkins GM, et al. Paclitaxel stent coating inhibits neointimal hyperplasia at 4 weeks in a porcine model of coronary restenosis. Circulation 2001;103: cine model

5 Grube E, Gerckens U, Rowold S, et al. Inhibition of in-stent restenosis by the Quanam durg-eluting polymer stent: two years follow-up. [abstract] $\mathcal{F}$ Am Coll Cardiol 2001;37(suppl A): $1 \mathrm{~A}-648 \mathrm{~A}$.

6 Drachman DE, Edelman ER, Seifert P, et al. Neointimal thickening after stent delivery of paclitaxel: change in composition and arrest of growth over six months. $\mathcal{F}$ Am Coll Cardiol 2000;36:2325-32.

7 Vodovotz Y, Kollum M, Cottin Y, et al. Delayed healing and increased thrombosis following intracoronary radiation in balloon injured porcine coronary arteries. Cardiovasc Radiat

8 Axel DI, Kunert W, Goggelmann C, et al. Paclitaxel inhibits arterial smooth muscle cell proliferation and migration in vitro and in vivo using local drug delivery. Circulation 1998; 96:636-45. Comment in: Circulation 1998;97:1651.

\section{WEB TOP 10}

www.heartjnl.com

These articles scored the most hits on Heart's web site during June 2001

1 Joint British recommendations on prevention of coronary heart disease in clinical practice December 1998;80(suppl 2):S1-29.

2 Matching the right drug to the right patient in essential hypertension Mf Brown

July 2001:86:113-20. (Education in Heart)

3 Angiotensin receptor blockers for chronic heart failure and acute myocardial infarction ffV McMurray

July 2001;86:97-103. (Education in Heart)

4 Acute myocardial infarction: primary angioplasty F Zijlstra

June 2001;85:705-9. (Education in Heart)

5 Long term results of mechanical prostheses for treatment of active infective endocarditis fM Guerra, MP Tornos, G Permanyer-Miralda, B Almirante, M Murtra, f Soler-Soler July 2001;86:63-8. (Interventional cardiology and surgery)

6 Guideline for the management of patients with acute coronary syndromes without persistent ECG ST segment elevation

February 2001;85:133-42.

7 Role of stenting in coronary revascularisation AH Gershlick

July $2001 ; 86: 104-12$. (Education in Heart)

8 Why is there discordance between calcific aortic stenosis and coronary artery disease? CM Otto, KD O'Brien June 2001 85;601-2. (Editorials)

9 The vitamin $D$ receptor genotype predisposes to the development of calcific aortic valve stenosis $\mathcal{F R}$ Ortlepp, $R$ Hoffmann, F Ohme, $\mathcal{F}$ Lauscher, F Bleckmann, P Hanrath June 2001;85:635-8. (Cardiovascular medicine)

10 Anatomic basis of cross-sectional echocardiography RH Anderson, SY Ho, Sf Brecker June 2001;85:716-20. (Education in Heart)

Visit the Heart website for hyperlinks to these articles, by clicking on "Top 10 papers" www.heartjnl.com 